\title{
Impact of atmospheric dust on Chinese peatland geochemistry
}

\author{
BARBARA FIAŁKIEWICZ-KOZIEŁ ${ }^{* 1}$, BEATA SMIEJA- \\ KRÓL $^{2}$, MARCIN SIEPAK ${ }^{1}$, JOLANTA DOPIERALSKA ${ }^{3}$, \\ KUNSHAN BAO \\ ${ }^{1}$ Adam Mickiewicz University in Poznań, Poland \\ (*basiafk@amu.edu.pl) \\ ${ }^{2}$ University of Silesia, Katowice, Poland \\ ${ }^{3}$ Poznan Science and Technology Park, Adam Mickiewicz \\ University Foundation \\ ${ }^{4}$ South China Normal University, Guangzhou, China
}

Impact of atmospheric dust of various origin on Chinese peatland using $\mathrm{Pb}, \mathrm{Sr}$ and $\mathrm{Nd}$ isotopes as well as REE and SEM mineralogical analysis was the subject of the study. The Motianling (Northeast China) is located at $1670 \mathrm{~m}$ asl, near the Chinese-Mongolian border. $64 \mathrm{~cm}$ peat core was dated using ${ }^{210} \mathrm{~Pb}$ and ${ }^{137} \mathrm{Cs}[1,2]$. REE were measured by ICP-MS (UAM), $\mathrm{Nd}$ and $\mathrm{Sr}$ isotopes - by TIMS (UAM), Pb isotopes were determined by Q-ICP-MS 7700x (NIGLAS).

The total $\sum$ REE in the minerotrophic part of profile (from $64-42 \mathrm{~cm}$ ) vary from 67 to $31 \mathrm{mg} \mathrm{kg}^{-1}$. Mineralogical analysis revealed the occurrence of weathered volcanic rocks in this part (phot.1). The influnce of surrounded quaternary volcanic rocks is supported by high $\varepsilon N d$ value (-3.26). After change from minerothrophic to more oligotrophic conditions the peatland was independent from the local bedrock weathering, what is manifested by much lower concentration of REE (7$\left.20 \mathrm{mg} \mathrm{kg}^{-1}\right)$ and lower $\varepsilon \mathrm{Nd}(-7.37 ;-8.11)$. The anthropogenic effect is visible from 1964, when the spheroidal aluminosilicates (SAP), indicating coal fired power plant activity, appeared for the first time, followed by abrupt decrease in ${ }^{206} \mathrm{~Pb} / 207 \mathrm{~Pb}$ isotopic signature to 1.167 . All isotopic signatures suggest the impact of western and northern sources of dust. The REE ratios are characteristic for eolian deposition signature similar to Gobi and northern Chinese deserts, while anthropogenic dust is supplied mainly by Russian industry.

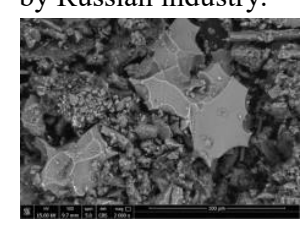

The research was supported by grant no. 2017/27/B/ST10/00428 from National Science Centre, Poland.

Phot.1 Tephra occurrence in the minerotrophic part of profile.

[1] Bao K. et al. (2010) J Environ Radioact 101,773-779.

[2] Bao K. et al. (2012) Sci Total Environ 431,33-45. 